William Siembieda

PhD, Department Head, CRP Cal Poly San Luis Obispo

Bruce Baird

Governor's Office of Emergency Services, California

Kenneth Topping

Former Director of Planning for the City of Los Angeles

Adjunct professor, CRP Cal Poly San Luis Obispo

\section{ACTIONS TOWARDS DISASTER RECOVERY A Global Planning Perspective}

This article explores recent thinking about disasters as a component of global, national and local development planning. It suggests ways of shifting emphasis from recovery to that of mitigation and risk reduction through community involvement and including risk assessment in the local plan making process.

Disaster reports appear in newspaper headlines with disturbing regularity. The number of events and the losses from disasters are increasing worldwide. The early January 2001 earthquake in El Salvador is quickly replaced with the late January 2001 earthquakes in India. In the next years the world experienced massive earthquake damage in Turkey and the loss of thousands of lives in an ancient village in Iran. Following these "natural" disasters in September 2001 is the World Trade Center's human-made disaster. In San Luis Obispo, the San Simeon earthquake of December 2003 caused significant damage particularly in Paso Robles, killing two people, collapsing 40 buildings, and shutting down the power for more than 10,000 homes.

Not only are the numbers of natural and manmade disasters increasing but also the cost in property and in human life. For natural disasters worldwide, the annual economic losses averaged $\$ 4.9$ billion in the 1960 s, $\$ 15.1$ billion in the $\$ 1980$ s and $\$ 75.9$ billion annually in the 1990s. The worst loss of life was 50,000 deaths in 1998. The September 11, 2001 attack on the World Trade Center in New York is a sad reminder of the collision between vulnerability and impact.

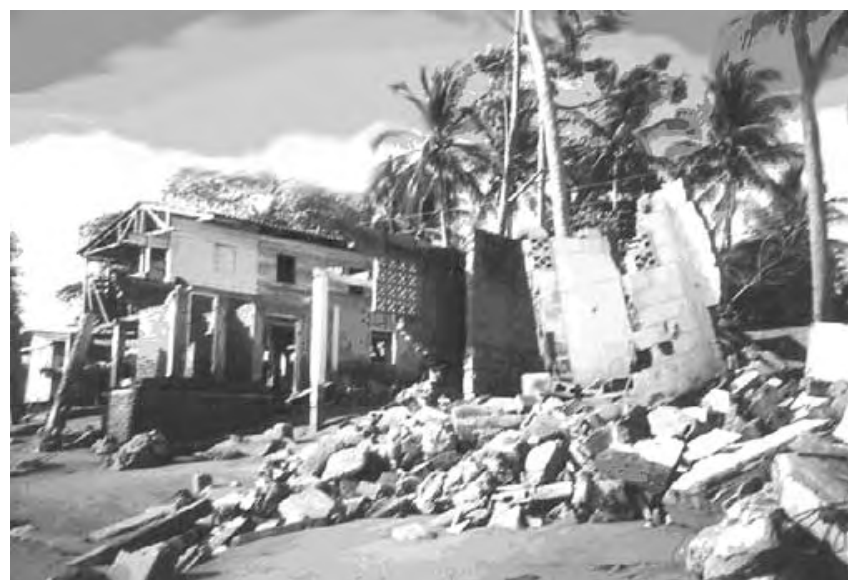

Damages on Honduras South Coast, Hurricane Mitch, 1998. (Photo: OES, California)
In part, this continued and inexorable increase in disaster losses is a function of world urbanization, where cities are located and the value of property. We are a more urban than rural world, developing without sufficient forethought in location subject to natural disasters.

Disasters are not totally solvable or controllable problems. They are physical, economic and social events to be mitigated, managed, learned from, and, to an increasingly greater extent, planned for. Disasters events fall into two broad categories and can impact whole regions, as well as cities and towns. The first is from human interaction: wars, famine, nuclear meltdown, and terrorism. The second is from human interaction with natural events: floods, earthquakes, hurricanes, etc. Actions taken by people, not nature, leading up to and following such events make them disasters.

\section{DISASTERS AND DISASTER RECOVERY}

Let us begin by establishing a dissster definition. Disasters are the result of an interaction between a hazard (such as an extreme natural event) and a vulnerable population. A disaster occurs when people suffer losses due to a hazardous

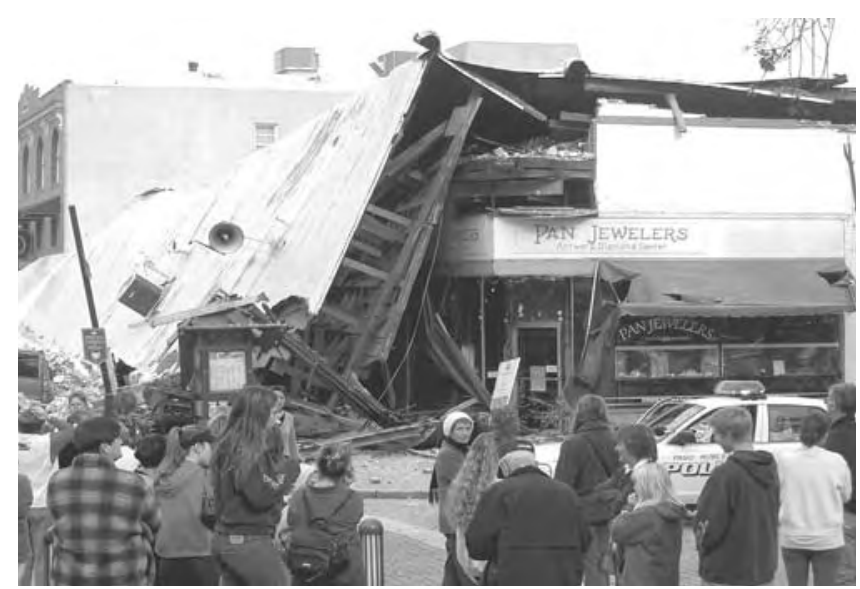

The Acorn Building in Paso Robles, after the San Simeon earthquake, 2003. (Photo: D. Stanfield) 
event that causes extreme damage to them, or their livelihood, and recovery is unlikely to occur without external aid. Disasters do not just happen. The actions leading up to them unfold over time and relate to the set of factors that place communities where they are at that point in time. This is an important distinction in linking any event with the level of vulnerability at the community or family level. There is socially constructed vulnerability built into our settlement system. Since there are limits to controlling extreme events (human or natural based), the need to examine methods to lessen or influence exposure to vulnerability becomes more important as a risk reduction strategy.

Recovery from a disaster is never an easy task. For poor communities in developing countries this task is more difficult because the majority of people have few assets (savings, insurance, construction equipment, ownership of property, etc.) to apply towards the recovery process. The economic cost of natural disasters can be twenty times higher as a percentage of gross national product (GNP) for developing countries than for industrialized nations. For example, annual flooding in Bangladesh impedes the GNP growth; while Vargas State in Venezuela has lost years of economic advancement from a single massive rain event. It is difficult to advance economic and social development when you to spend large parts of the public budget rebuilding roads, school and bridges.

\section{PATTERNS OF RECOVERY}

According to the World Bank, there is now recognition in government and international agencies of the need to incorporate natural hazard mitigation and risk reduction in development planning. Until recently there has not been much interest among policy analysts, especially in economically advanced, "first world" countries. Part of this is due to the unique ability of first world countries to put in place strong systems of risk identification, risk education and risk transfer.

Risk identification provides the basis for risk reduction. Risk transfer (mainly private insurance schemes and claims on government assistance programs such as FEMA) requires a level of wealth and financial infrastructure to function well. For the U.S. more than fifty percent of the total private property loses are paid by private insurance; while in Asia, which in 1997 accounted for over half of the world property losses, private insurance covers only two percent of the losses.

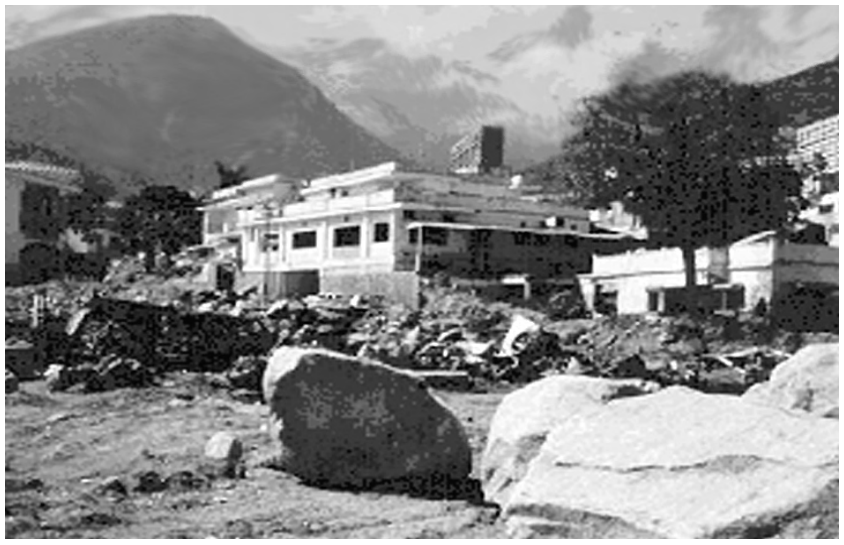

Alluvial flooding destroys coastal towns in Venezuela, 1999. (Photo: OES, California)

Tropical rains and flooding destroying shacks in a squatter settlement, Rio de Janeiro. (Photo: www.oglobo.com)
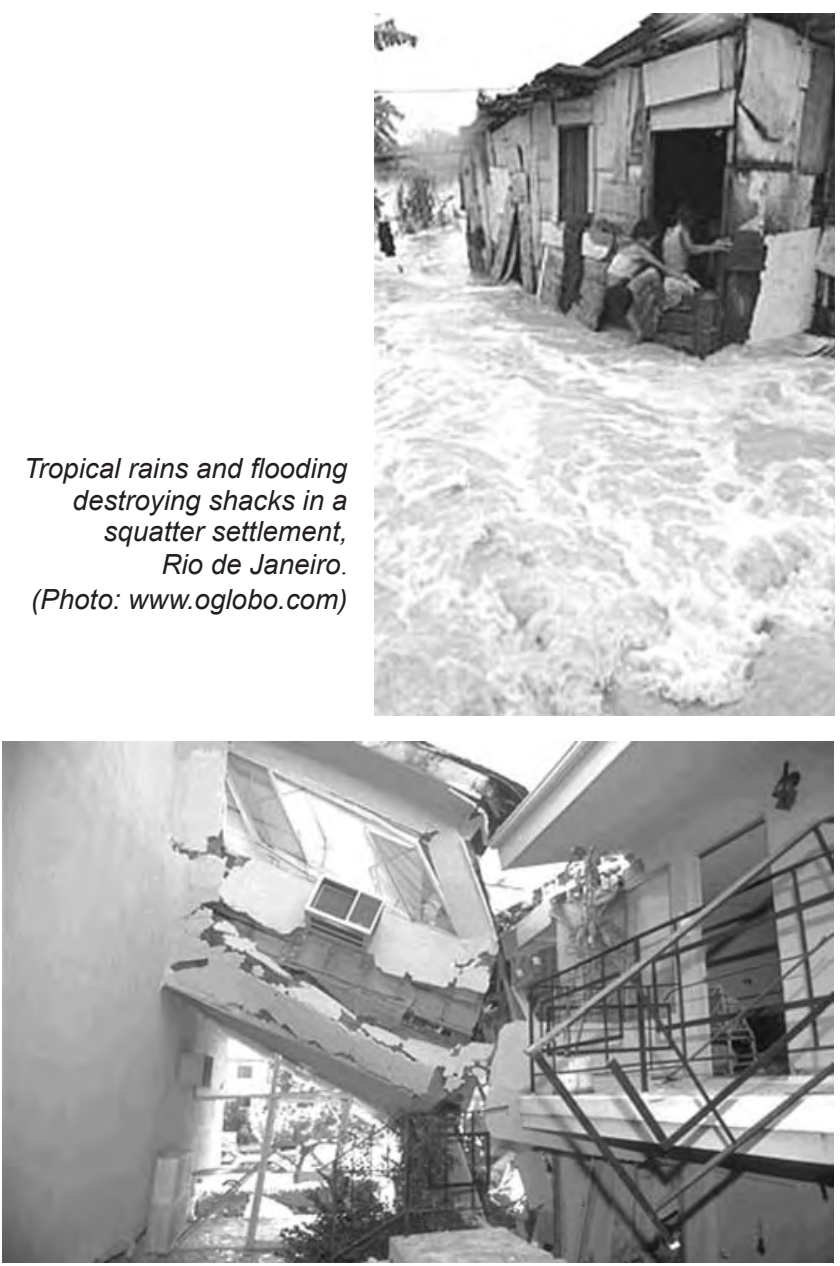

Destruction by the Northridge earthquake in Los Angeles, 1994. (Photo: OES, California) 


\section{THE CLASSIC RECOVERY MODEL}

Disasters are not new phenomena. They have however, become more prominent as the world continues to urbanize, and according to the United Nation's Urban Development Unit will increase in number in this century. Over time, a set of institutional mitigation/prevention and recovery procedures has evolved to address disaster events. This set can be called the classical model for disaster recovery. There are generally four stages to disaster recovery cycle including (1) the "emergency response" stage which emphasizes measures for the rescue of people, removal of debris and provisions of temporary shelter and food, (2) the "restoration stage" which emphasizes restoration of public facilities and services, (3) the "return to normalcy" stage characterized by the attempt at replacement or reconstruction of capital stock and economic activity to pre-disaster levels, and (4) the "redevelopment or reconstruction" stage featuring initiation of reconstruction that involves economic growth and physical redevelopment.

In practical terms the post-recovery community (especially the site most impacted) often will be different in appearance, form and perhaps utilization of social and economic resources from the pre-disaster community. The disaster event furnishes the community an opportunity to correct problems, which might lead to future disaster impacts if left unattended. One may ask when (if at all) the 'equity' function comes into play in disaster policy. Equity, in this context, needs to be understood in terms of vulnerability which involves the ability to recover from a particular type of 'shock' or injury in a given period of time with the physical, social, and economic resources available. Vulnerability however, is not evenly distributed. Poor and marginalized people (such as caste groups in India) carry with them higher degrees of vulnerability than other groups in society. The equity is linked with how local and non-local policy analysts can address the vulnerability of specific populations in their community, city or region in terms of the types of natural events most likely to occur.

Based on experiences in Asia and Latin America the classical model can be improved by adding to it other kinds of activities. These include: risk assessment, mitigation measures, identification of special done group and emphasizing post disaster planning. Risk assessment and mitigation task are best carried out in the pre-disaster period.

\section{EVOLVING GLOBAL PERPECTIVE}

Worldwide there is an overall sense of for the need to decentralize disaster relief authority. This is a significant movement away from the notion of "single high level institutions" as the best means of controlling human settlement supported by Habitat I, the first UN Conference on World Settlements convened in 1976. The experiences in Turkey, India, Venezuela, and Honduras teach us a lesson. There is a need to strengthen the regulatory structures that control and oversee how buildings are planned and constructed and to listen more closely to local groups in the community to determine the level and extent of built environment vulnerability. Thus, in countries such as Turkey where $45 \%$ of the population live in high risk areas there has been a call to privatize the design and construction supervision activities in the most vulnerable cities. While this could be considered an indictment of the local government's capacity to serve the populace, it does reflect the extent of concern over reducing the recurrence of natural disasters related losses and a willingness to recognize the limits of state operated regulatory systems.

For the world's larger cities efforts are underway to establish common disaster management tools under what is known as the Disaster Management Master Plan. This plan has five elements: assessment, preparedness, response, relief and mitigation, and expertise acquisition. To make such a plan work, central governments must establish the needed strategies to decentralize decisions and to provide adequate resources. The fact that disaster master planning is being discussed in larger cities is a positive step.

\section{Central American Examples}

Legislation signed in Nicaragua in 2000 created an entirely new system of disaster prevention. Under this system, mitigation and management is based on working at the community level with the country's 152 municipal governments and is assisted by a coordinating national agency. With regional operations, local disaster committees work to link their needs to a regionalized approach in an effort to secure improvements that lessen vulnerability. The limits to this approach are resource based, not organizational. A national disaster mitigation plan is now being developed in Nicaragua.

In Honduras, 1999 legislation authorized a new civilian agency (COPECO) for disaster recovery, separating this 
function from the military. With the assistance of World Bank resources, this will lead over time to the municipalization of emergency services in the country so that local stakeholders will play a greater role overall. The Organization of American States (OAS) has adopted sectorial improvements focusing first on the local school system to make the buildings secure places that can withstand a disaster event and also to make disaster education part of the curriculum. This approach has particular merit in that local schools are closely linked to the household level and are part of building social capital. A generalized model of the evolving Central American approach is shown in Graphic \#1 .

\section{The Kobe Case}

The post-disaster planning period is an opportunity for national support of post-disaster activities designed to empower local authorities to incorporate local realities and include voices of more stakeholders. It also provides space for new actors to participate, as was the case in Kobe, Japan, where the Machizukuri process of town design, building and citizen participation was implemented as a result of the earthquake of 1995 that killed over 6,000 people, injured 40,000, and displaced 300,000 households in Kobe.

In rebuilding after the earthquake, the major role of the central government was to finance reconstruction of roads, the port, railways, parks, and public schools. The major role of city governments was to guide the urban planning activities during the rebuilding process. Seventeen restoration promotion districts were quickly established in Kobe City and other affected cities. Within three to four years over 160,000 housing units were constructed in Kobe and nearby cities.

However, in the rush to restore normalcy the urban pattern was changed by the construction of many high-rise residential buildings that replaced the low wooden housing destroyed units. This brought about permanent changes in living environments. Elderly people felt especially strong impacts and had difficulty adapting to the new conditions. This was also true for lower income people who could not afford such modernized replacement housing.

The first planning phase undertaken by Kobe City in achieving this remarkable recovery was made during the two-month period immediately following the earthquake. City officials made basic decisions on citywide plans for major centers, arterial roads, and parks. The second phase was at a neighborhood level, emphasizing review of local street and park plans with local residents through the Machizukuri (community building) citizen participation process. This took two to three years. The third phase, finalization and adoption of plans, took several more years, and implementation has continued. Nine years after the quake the major recovery in broad physical terms was complete while the process of local neighborhood and household recovery continues. Today there are new

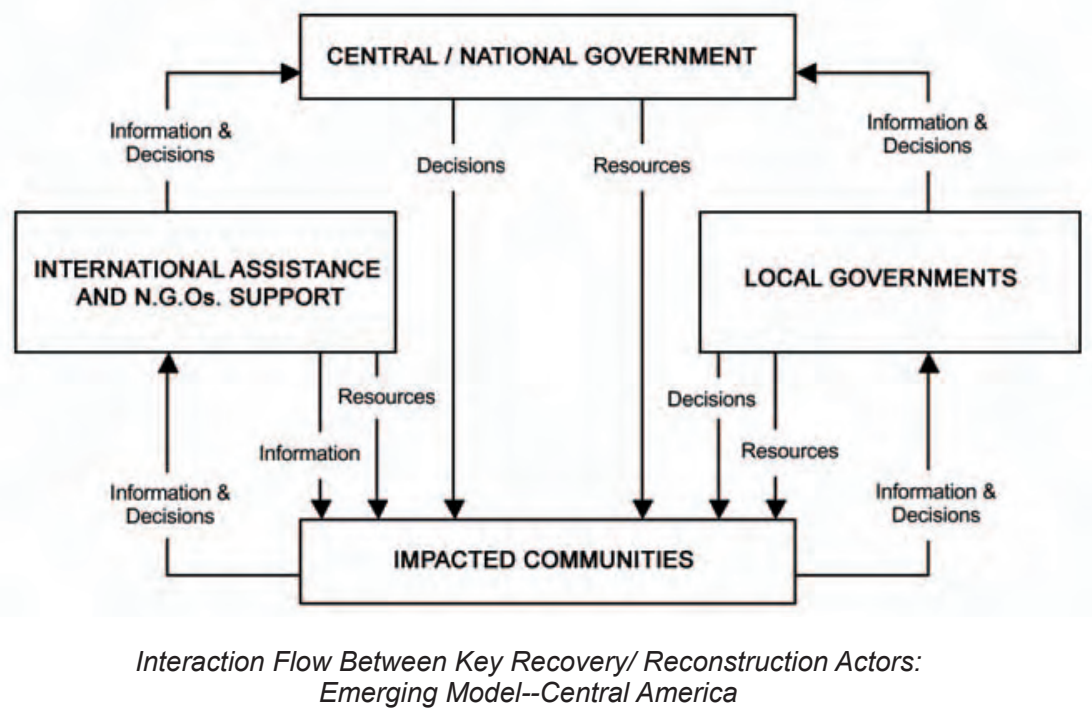


mixed-use housing and retail towers, a memorial museum, waterfront parks, and a changed community.

What can we learn from this experience in preparing for future disaster recovery in New York or other world communities? One applicable lesson is that it may not be possible to restore familiar surroundings exactly as they were. All segments of the community do not hold a common image. Another important lesson is that involvement of citizens in planning for development can be not only useful but also truly beneficial in bringing about community betterment. A third lesson is that disaster recovery experiences from other countries, emphasizing as they do the creative use of all types of assistance, can be useful in improving pre- and postdisaster planning effectiveness.

\section{USA Context}

In the US there is a slow shift towards greater appreciation of disaster mitigation planning. An example of this involves changes in the U.S. Army Corp of Engineers approach away from attempting to "tame" rivers and reclaim lands for urban uses with dams and levees. Part of the shift comes from the growing recognition by the U.S. Federal Emergency Management Agency (FEMA) and other federal agencies that disasters always are local in impact.

In 1998 there were 98 major disasters declared involving 34 of the 50 states. That year FEMA incurred disaster assistance payment obligations of more than $\$ 3$ billion. Direct recovery costs from the Northridge earthquake event in California were in excess of $\$ 12$ billion with 57 percent being covered by private insurance and 25 percent in U.S. Small Business Administration (SBA) loans. Even with massive assistance from many sources the most marginalized groups living in Northridge received less relief than the middle class and mainstreamed groups.

To address this trend FEMA began Project Impact: Building Disaster Resistant Communities. This effort was based on three principles: preventive action must be decided at the local level, private sector participation is vital, and long term efforts and investments for prevention measures are essential. The Disaster Mitigation Act of 2000 provided incentives and guidance for urban planners to develop local hazard reduction plans.

At the state level, California has shown significant leadership. One example, is the Disaster Recovery Reconstruction Act of 1986, passed by the California legislature following a review of impacts of the 1985 Mexico City earthquake disaster. This act authorizes cities, counties and other entities to prepare in advance for disasters and for the orderly recovery and reconstruction of the community or region. The act provides guidance for cities to prepare a hazard vulnerability analysis and can be part of the state-mandated general plan safety element. A contingency plan and a pre-event ordinance approach provide local authorization for recovery and reconstruction which can be invoked as soon as possible after an event.

\section{KEY TO SUCCESS: EFFECTIVE PRE-EVENT STRATEGIES}

The theme of pre-event planning identified by the 1986 California statute was significantly enhanced in a milestone publication prepared jointly by FEMA and the APA, Planning for Post-Disaster Recovery and Reconstruction, PAS Report 483/484, December 1998. The first seven chapters focus on planners' roles, disaster operations, planning policies, planning processes, planners' tool kit, and legal and financial issues as well as hazard identification and risk assessment. The final five chapters contain a series of case studies reflecting lessons learned from disasters in various U.S. cities.

Recovery after a major disaster may be the most significant challenge a local jurisdiction will ever face. Therefore the better a community is prepared with procedures and predisaster inventories of readily accessible resources useful to recovery and reconstruction the easier it will be to meet the challenge. For local, county and even regional planning staffs it is important to understand who will take on which role after a disaster event and how to provide support for the "temporary" organization in meaningful ways.

\section{SUMMARY OBSERVATIONS}

Are urban planners needed in disaster mitigation and disaster recovery? The answer is YES. Would these activities be better served by better training of civil engineers, organizational managers, national policy analysts, and social/health service providers? The answer is definitely NO, if such training precludes involvement of planners in the recovery process..

The reasons for these answers are many. To begin with, urban planners take a broader, more systematic approach to the challenges of the city and human settlements. Urban planners also think about implementation; how things 
get done, how the pieces fit together, and what trade-offs between scenarios may be necessary. Urban planners also know how to create alternatives and foster debate with a critical eye to equity considerations.

Moreover, urban planners are involved in drawing citizens into the process of creating visions for better futures for the community more so than creating visions by themselves. In doing so the idea of simply "returning to normalcy" usually is not an acceptable option. The fact that urban planners 1) use information from many sources, 2) emphasize integrative concepts, 3) are sensitive to equity issues, and 4) make attempts to provide synergy between solutions proposed to all issues makes their professional involvement with disaster mitigation and recovery particularly valuable.

For too long, urban planning has left the subject matter of disaster mitigation and proactive involvement in disaster recovery to others. With the prospect of an increasing number of disasters in the $21^{\text {st }}$ century, it is time for all of us to make a contribution to this important area of community betterment.

Note: This article is a revised version of an article published in Interplan (publication of the APA International Division) \# 69, January 2002.

\section{READINGS}

Anderson, Torken. Globalization and Natural Disasters: An Integrative Risk Management Perspective. Paper at "The Future of Disaster Risk: Building Safer Cities" conference, The World Bank, 2002.

Blaikie, Piers et al. At Risk: Natural Hazards, People's Vulnerability and Disasters. London: Routledge, 1994.

Burby, R. et al. "Unleashing the Power of Planning to Create Disaster Resistant Communities". Journal of the American Planning Association, 1999.

Berke, Phillip and Timothy Beatley. Planning for Earthquakes: Risk, Politics, and Policy. Baltimore, MD: Johns Hopkins University Press, 1992.

Comerio, Mary C. Disaster Hits Home: New Policy for Urban Housing Recovery, Berkeley, CA: University of California Press. 1998.
Cuny, Frederick C. Disasters and Development. New York, NY: Oxford University Press, 1983.

Haas, J. E., Kates, R. and Bowden, M. (Eds.) Reconstruction Following Disaster. Cambridge, Massachusetts: MIT Press, 1977.

Kreimer, Alcira and Arnold, Michael (Eds.) Managing Disaster Risk in Developing Countries. Disaster Risk Management Series \# 2. Washington, D.C: The World Bank, 2000.

Siembieda, William and Baird, Bruce. Enhancing the Disaster Recovery Model. Background paper for The Unite Nations Global Report: Cities in a Global World. London: Earthscan Books, 2001.

Siembieda, W., Cremeen, R. and Baird, B. "Desastres: hacia un paradigma enfacado a la recuperación. Ciudades \# 52 Puebla, México: Red Nacional de Investigacion Urbana. Octubre-diciembre, 2001.

Schwab, James et al. Planning for Post-Disaster Recovery and Reconstruction. Chicago, Ill.: American Planning Association (PAS Report) 483/484, December 1998.

Topping, Kenneth C. Urban Planning During Rebuilding: The Machizukuri Experience. Invited paper published in The Presentation of Global Assessment of Earthquake Countermeasures, Hyogo Prefecture, Kobe, Japan, January $10-14,2000$.

United Nations Development Program. Reducing Risk: A Challenge for Development. New York: The United Nations, 2004. 